\title{
A study on understanding of employee engagement practices: comparison between banks and higher education institutions
}

\author{
Anil Kumar Singh ${ }^{1}$, Priyender Yadav ${ }^{2}$ \\ ${ }^{1}$ Institute of Business Management, GLA University, Mathura, 281406, India \\ anil.singh.kr@gmail.com \\ ${ }^{2}$ Institute of Business Management, GLA University, Mathura, 281406, India \\ priyender@gmail.com
}

\begin{abstract}
Employee engagement has been high on agenda of a number of researchers and organizations in the recent years. A successful employee engagement strategy helps creating a community at the work place and not just a work force. An engaged employee is aware of business context, and works with colleagues to improve performance within the job for the benefit of the organization. The organization must work to develop and nurture engagement, which requires a two-way relationship between employer and employee.' Thus Employee engagement is a barometer that determines the association of a person with the organization. As a researcher this concept requires careful investigation and the interest, therefore is to extract the determinants of employee engagement and to understand what all factors contribute to this concept. Literature has proved that it is the trust which measures the degree of employee engagement, so in the present study the researchers have tried to find out the effect of trust and value on employee engagement.

As banks and higher educational institutions offer a comparative platform to study the practices because both are in service sectors and the competencies required are relatively same. Further, these organizations are heavily focused on Human Resources as an asset and their image is directly associated with employees acts and behaviors.

So in the present paper the researchers have tried to explore the rationale of employee engagement practices through data analysis by using SPSS and Excel . For the purpose the data has been collected through questionnaire and statistical tools like multivariate analysis and ANOVA etc has been used.
\end{abstract}

Indexing terms/Keywords

Engagement, Employee Engagement, Commitment, Motivation , Loyalty.

\section{Academic Discipline And Sub-Disciplines}

Management: Strategic Human Resource Management

\section{SUBJECT CLASSIFICATION}

Management

TYPE (METHOD/APPROACH)

Exploratory/ Sescriptive

\section{Council for Innovative Research}

Peer Review Research Publishing System

Journal: International Journal of Management \& Information Technology

Vol.4, No.2

editor@cirworld.com

www.cirworld.com, member.cirworld.com 


\section{INTRODUCTION}

The word 'engagement' has taken on a variety of meanings, and it is important that we comprehend these meanings in order to understand both research and practitioner perspectives on engagement - not least because some systematic differences exist between the two. Most often employee engagement has been defined as emotional and intellectual commitment to the organization( [3],[38],[46]) or the amount of discretionary effort exhibited by employees in their job [14]. Employee engagement is the thus the level of commitment and involvement an employee has towards their organization and its values. An engaged employee is aware of business context, and works with colleagues to improve performance within the job for the benefit of the organization. The organization must work to develop and nurture engagement, which requires a two-way relationship between employer and employee.' Thus Employee engagement is a barometer that determines the association of a person with the organization.

Research has repeatedly demonstrated the employee engagement links between the way people are managed, employee attitudes and business performance [53]. This highlights the problems of comparability caused by differences in definition. Furthermore, whilst it is acknowledged that employee engagement has been defined in many different ways, it is also argued the definitions often sound similar to other better known and established constructs such as 'organisational commitment' and 'organisational citizenship behaviour' (OCB) [39].

A modernized version of job satisfaction, Schmidt et al.'s influential definition of engagement was "an employee's involvement with, commitment to, and satisfaction with work. Employee engagement is a part of employee retention." Consistent with this approach, [42] described engagement as a positive, fulfilling, work-related state of mind characterized by vigor, dedication, and absorption. Although engagement shares some aspects of job satisfaction and organisational commitment, the concept of engagement is distinct and might be expected to predict a wider range of outcomes. For example, satisfaction among employees is of course desirable, but satisfied employees may not necessarily display vigour in their work. Employees who are committed to their organisations may not always have an in-depth commitment to their job.

The closest relationship with engagement is 'affective' commitment as explained by [47]. This type of commitment emphasizes the satisfaction people get from their jobs and their colleagues, and the willingness of employees to go beyond the call of duty for the good of the organization. According to SHRM (Society of Human Resource Management) the cost of replacing one $\$ 8$ per hour employee can exceed $\$ 3,500$, which gives companies a strong financial incentive to maintain their existing staff members through strong employee engagement practices

The defining distinction is that employee engagement is a two-way Interaction between the employee and the employer, whereas the earlier focus tended to view the issues from only the employee's point of view. Definitions of engagement, or characteristics of an engaged workforce, focus on motivation, satisfaction, commitment, finding meaning at work, pride and advocacy of the organization (in terms of advocating/recommending either the products or services of the organisation, or as a place to work).

\subsection{Conceptual Framework}

W. D. Kahn is credited with conceptualizing the major components of employee engagement. His model proposes that engagement differs from basic job involvement, in that it focuses not on worker skills but, rather, on how one commits $\mathrm{him} /$ herself during the performance of the job. Engagement entails the active use of emotions in addition to the simple use of cognition while completing work tasks [35]. The major propositions of the model are that people express themselves cognitively, physically, and emotionally while performing their work roles. The model proposes that, in order for individuals to fully engage with their job, three psychological conditions must be met in the work environment: meaningfulness (workers feeling that their job tasks are worthwhile), safety (feeling as though the work environment is one of trust and supportiveness), and availability (workers having the physical, emotional, and psychological means to engage in their job tasks at any given moment) [27].

\subsection{Elements of Employee Engagement}

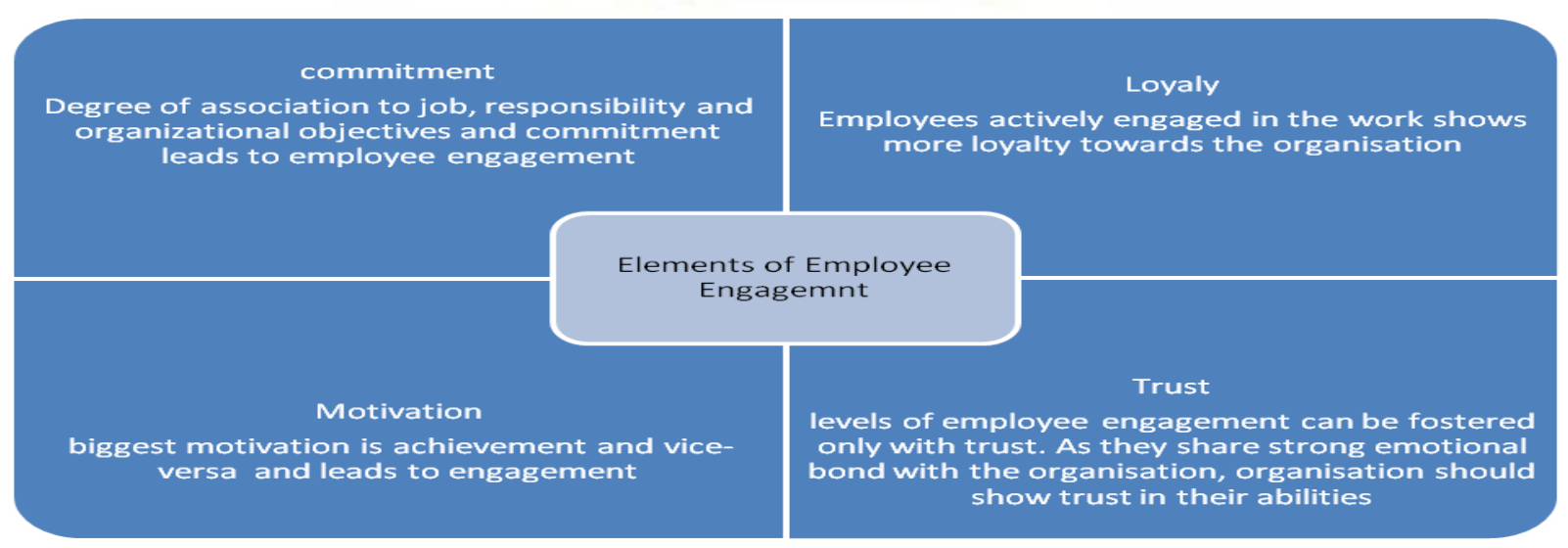

Fig 1: Elements of Employee Engagement 


\subsection{Phases of Employee Engagement}

Employee engagement is a concept that has begun to grab the attention of the corporate world for past few years. When put simply, higher levels of employee engagement mean higher profitability of the organisation.

Employee engagement is critical. Highly productive organisations have understood this fact a long ago where mediocre and low performing organisations have just started taking it seriously. It makes sense to engage employees and make them find a meaning in what they do.

\subsubsection{Attract}

The first phase of the employee engagement cycle is attracting the best talent from the industry. This phase involves creating a positive impression about the work culture and employee career as a potential employer. Another aspect spreading the reputation of an organisation is its employees. They are not only the employees but also are regarded as internal customers. Their job and career satisfaction speaks about their workplace. Therefore, they should not be taken for granted. Besides attracting the talent from the outside, it is important to keep the existing employees attracted towards the organization.

\subsubsection{Acquire}

The acquire image involves more than one thing. It includes (1) the way the potential candidates are interacted while advertising a position; (2) keeping the promises that were made while hiring them and (3) providing the new joiners a right kind of work culture. When an organisation advertises a position, interested candidates apply. The way their applications are created, the reaction of the organisation and the manner in which they are approached speak a lot about the image and work culture of an organisation.

Hiring the best talent not only serves the purpose. During their honeymoon or initial period with the organisation, the company must try to keep all the promises that were made during the selection process. Besides this, they should feel happy and satisfied when their expectations are tested against the reality. Providing the right kind of culture also plays an important role in keeping them engaged. The whole idea is to prepare them to perform their best by giving them challenging tasks right from the beginning. It's like developing a habit or culture right from the time they decide to work with the organisation.

\subsubsection{Advance}

Continuous moving the talent is the last but an unending phase. It not only involves promoting the employees to a higher designation along with salary increments but also growing them in other tangible and intangible ways. Job rotation can help them grow in experience, responsibility and belongingness but only when it is done right. Advancing the employees in every aspect, be it monetary or non-monetary, is the key to retain people and develop their overall personality.

\subsection{Drivers of Employee Engagement}

1.4.1 Work/Job Role - Employees must see a link between their role and the larger organization goal. Understanding this linkage provides an intrinsic motivation and increased engagement. Most employees will come to work on time without possessing a sense of belonging and will try and complete assigned tasks even without possessing that sense achievement on completion of task. However, an employee that sees a clear linkage on how his/her role contributes to the organization will go the extra mile and help create organization wealth.

1.4.2 Work Environment/Organization Culture - The bond between an employee and the organization is cemented when the employee identifies with the culture of the organization. An employee is engaged and motivated to stretch beyond the call of duty if he/she finds the work environment enabling and supportive.

1.4.3 Rewards and Recognition - The bottom line is that people work to earn which helps fulfil ambitions. Equitable pay coupled with rewards and recognition programs enhances motivation and leads to commitment and engagement.

1.4.4 Learning and Training Opportunities - "People Enjoy Learning." This is especially true in the case of today's millennial workforce that constantly looks at enhancing knowledge and skill. Skill and Knowledge enhancement is not just important for the employees but providing a learning culture is essential for organizations to remain relevant in the constantly changing business landscape.

1.4.5 Performance Management - An effective performance management system contributes positively to employee engagement. Goal setting lies at the root of any performance management system. Clearly articulated goals, a fair and just means to judge performance and timely, rational feedback are critical elements in creating a bond between the employee and his/her organization.

1.4.6 Leadership - It is a well recorded fact that most resignations happen because the employee is not satisfied with his/her 'boss.' An organization that spends time and effort in grooming leaders who are aligned to its goals, culture and people invests well. New age industries have a young and dynamic workforce that looks for autonomy in decision making, increased responsibility and accountabilities. 
1.4.7 Other Factors - Clear and open communication, quality of interaction with peers, collaboration, organization policy, organization performance are all contributing factors to employee engagement.

\section{LITERATURE REVIEW}

One of the most influential studies of engagement was carried out byKahn. Conceptually, Kahn began with the work of Goffman (1961) who proposed that, "people's attachment and detachment to their role varies" [27]. However, Kahn argued that Goffman's work focused on fleeting face-to-face encounters, while a different concept was needed to fit organisational life, which is "ongoing, emotionally charged, and psychologically complex"

To gain further understanding of the varying levels of attachment individuals expressed towards their roles, Kahn examined several disciplines. It was found that psychologists [16] , sociologists [18] and group [50] had all recognised the idea that individuals are naturally hesitant about being members of ongoing groups and systems. As a result they "seek to protect themselves from both isolation and engulfment by alternately pulling away from and moving towards their memberships". The terms Kahn uses to describe these calibrations are 'personal engagement' and 'personal disengagement', which refer to the "behaviours by which people bring in or leave out their personal selves during work role performances" [27]. These terms developed by Kahn integrate previous ideas taken from motivation theories that people need self-expression and self-employment in their work lives as a matter of course ([1],[34]).

An alternative model of engagement comes from the 'burnout' literature, which describes job engagement as the positive antithesis of burnout, noting that burnout involves the erosion of engagement with one's job [35]. According to Maslach et al, six areas of work-life lead to either burnout or engagement: workload, control, rewards and recognition, community and social support, perceived fairness and values. They argue that job engagement is associated with a sustainable workload, feelings of choice and control, appropriate recognition and reward, a supportive work community, fairness and justice, and meaningful and valued work. Like burnout, engagement is expected to mediate the link between these six work-life factors and various work outcomes. May [36] findings support Maslach [35] notion of meaningful and valued work being associated with engagement, and therefore it is important to consider the concept of 'meaning'

According to Holbeche and Springett [24], people's perceptions of 'meaning' with regard to the workplace are clearly linked to their levels of engagement and, ultimately, their performance. Holbeche and Springett argue that high levels of engagement can only be achieved in workplaces where there is a shared sense of destiny and purpose that connects people at an emotional level and raises their personal aspirations.

Saks [42],says that a stronger theoretical rationale for explaining employee engagement can be found in social exchange theory (SET). SET argues that obligations are generated through a series of interactions between parties who are in a state of reciprocal interdependence. A basic principle of SET is that relationships evolve over time into trusting, loyal, and mutual commitments as long as the parties abide by certain 'rules' of exchange [11]. Such rules tend to involve reciprocity or repayment rules, so that the actions of one party lead to a response or actions by the other party. For example, when individuals receive economic and socio-emotional resources from their organisation, they feel obliged to respond in kind and repay the organisation (ibid). This is consistent with Robinson [40] description of engagement as a two-way relationship between the employer and employee.

In recent years, more studies have begun to look at the antecedents and consequences of employee engagement. Practitioners and academics tend to agree that the consequences of employee engagement are positive [42]. There is a general belief that there is a connection between employee engagement and business results; a meta-analysis conducted by Harter [20] confirms this connection. They concluded that, "...employee satisfaction and engagement are related to meaningful business outcomes at a magnitude that is important to many organisations". However, engagement is an individual-level construct and if it does lead to business results, it must first impact individual-level outcomes. Therefore, there is reason to expect employee engagement is related to individuals' attitudes, intentions, and behaviours.

Gallup cites numerous similar examples. The International Survey Research (ISR) team has similarly found encouraging evidence that organisations can only reach their full potential through emotionally engaging employees and customers (ISR 2005). In an extension of the Gallup findings, Ott cites Gallup research, which found that higher workplace engagement predicts higher earnings per share (EPS) among publicly-traded businesses. When compared with industry competitors at the company level, organizations with more than four engaged employees for every one actively disengaged, experienced times more growth in EPS than did organisations with a ratio of slightly less than one engaged worker for every one actively disengaged employee.

The findings can be considered as reliable as the variability in differing industries was controlled by comparing each company to its competition, and the patterns across time for EPS were explored due to a 'bouncing' increase or decrease which is common in EPS. Whilst this research does not show investors and business leaders exactly what organizations are doing on a day-to-day basis to develop engaged employees, the findings do demonstrate differences in overall performance between companies, and Gallup's meta-analyses present strong evidence that highly engaged workgroups within companies outperform groups with lower employee engagement levels, and the recent findings reinforce these conclusions at the workgroup level. The meta-analysis study shows that top-quartile business units have 12 per cent higher customer advocacy, 18 per cent higher productivity, and 12 per cent higher profitability than bottom-quartile business units. In contrast, bottom-quartile business units experience 31 per cent to 51 per cent more employee turnover and 62 per cent more accidents than those in the top quartile of workplace engagement. This research into EPS provides a degree of proof that employee engagement correlates to crucial business outcomes.

\section{NEED OF THE STUDY}

Highly engaged employees make a substantive contribution to their agency and may predict organizational success [42]. But the reverse holds true as well. Disengaged employees can be a serious liability. Ayers [55] compares disengagement 
to a cancer that can slowly erode an agency. Customer satisfaction, employee retention, and productivity are all at risk unless burnout and disengagement can be controlled. Unfortunately, some studies show that workers in general are not engaged with their jobs. Frauenhiem's [15] review of a recent Sibson Consulting Firm survey found that satisfaction scores with all major categories of work in the U.S. have dropped, and just over half of the respondents in the study rated themselves as engaged, or highly engaged.

This lack of engagement affects large and small organizations all over the world, causing them to incur excess costs, to under perform on crucial tasks, and to create widespread customer dissatisfaction (Rampersad, 2006). Disengagement can affect the financial solidarity of an agency as well. Ayers (2006) explains the potential monetary impact by estimating that if an organization has employees who are only 30\% to $50 \%$ percent engaged then $50 \%$ to $70 \%$ of the payroll is an ineffective expenditure of agency resources. And not only are these disengaged staff members taking up resources in pay and benefits, they also work against the best interests of the agency and can actually turn committed employees against the organization [55].

To further emphasize how widespread this problem is and how critical it can be, consider a recent Gallup study [8] in which hundreds of companies were surveyed. Results from their surveys showed that $54 \%$ of workers were not engaged and $17 \%$ were actively disengaged. In other words, the companies surveyed were operating on only a fraction of the resources that should be available to them.. In this study, the most engaged work groups were noted to be the most productive and the rest were shown to be mediocre or, in some cases, destructive [8].

The earlier discussions bring out contradictions in the concept and determinants of employee engagement. As a researcher this concept requires careful investigation. Interest, therefore is to extract the determinants of employee engagement and to understand what all factors contribute to this concept. Literature has proved that it is the trust which measures the degree of employee engagement so in this study trust is considered as a dependent variable. Enhanced trust is a measure of indicator of engagement practices. Also the contextual and conceptual clarity can be achieved when the same model can be contrasted in different sectors of industry.

Banks and higher educational institutions offer a comparative platform to study the practices because doth are in services sector and the competencies required are relatively same. Convenience in terms of data collection is yet another variable which prompts us to investigate in this domain. Further, these organizations are heavily focused on Human Resources as an asset and their image is directly associated with employees acts and behaviors.

Thus, this research will first identify the factors which are perceived to be of significance in employee engagement and also will guide us to group the factors into meaningful and logical combinations. These factors subsequently on the basis of literature are identified as dependent and independent. Then an attempt will be made to understand whether bank and educational sector policies of organizations focus in the similar way on the factors of employee engagement.

This study will utilize SPSS as a tool for dimension reduction and further ANOVA and multiple regression analysis will be used to arrive at conclusions. Based on the nature of phenomenon to be investigated the research methodology is described in detail, in the subsequent chapters.

\subsection{Objectives}

- To investigate awareness about the concept of Employee Engagement.

- To identify factor leading to employee engagement.

- To identify a suitable proxy for measuring Employee Engagement.

- To compare employee engagement practices in banking and institutions of higher education

\section{RESEARCH METHODOLOGY AND DATA COLLECTION}

From literature review variables were identified and after ensuring the face validity, a questionnaire was developed with 40 questions. 140 questionnaires were filled by targeted respondent. Factor analysis was carried out and after dimension reduction 18 questions were grouped into in to 5 factors. After EFA the sample size was 300,150 from bank and 150 from institutes. Our research area was Mathura and Agra region. Our sample size is 300, 150 from bank and 150 from institutes. This research is a cross-sectional study that covers the period of 2013 when the data was collected. Interpreting the results when we carry out multiple regression analysis with trust and value as a dependent variable we find the model justifying the research hypothesis. Focus was on the employee engagement. The convenient method of sampling was adopted.

\subsection{Hypothesis Formulation}

A hypothesis is a tentative explanation that accounts for a set of facts and can be tested by further investigation. Quantitative researchers will design studies that allow us to test hypotheses. One can collect the relevant data and use statistical techniques to decide whether or not to reject or provisionally accept the hypothesis. Accepting a hypothesis is always provisional since new data may cause it to be rejected later on.

According to the research objectives the following hypothesis are formulated.

$\boldsymbol{H}_{C L T S}$ : Commitment leads to increase in trust and respect

$H_{v v L T S:}$ Value and voice leads to increase in trust and respect

$\boldsymbol{H}_{\text {ALTS: }}$ Alignment leads to increase in trust and respect

$\boldsymbol{H}_{C L T S}$ : Culture leads to increase in trust and respect

$\boldsymbol{H}_{P D}$ : There is no significant difference between perceived determinants between employees of banks and teachers of higher educational institutions. 
$\boldsymbol{H}_{v c:}$ The variables contributing to trust and respect do not vary among employees of banks and teachers of higher educational institutions.

\subsection{Research Design}

Thus Descriptive research design is used to describe the employee engagement practices comparison between bank and higher education. Descriptive research is used to obtain information concerning the current status of the phenomena to describe "what exists" with respect to variables or conditions in a situation. The methods involved range from the survey which describes the status quo, the correlation study which investigates the relationship between variables, to developmental studies which seek to determine changes over time.

\subsection{Resuls of Factor Analysis (EFA)}

Exploratory factor analysis (EFA) was conducted to investigate whether the data reflected the constructs, dimensions or factors 3 and whether individual items were loaded on their appropriate constructs as intended. The data was subjected to iterative EFA using SPSS v.19 software. EFA was used to identify patterns, structure and purify the scale measures on the pooled sample.

A combination of methods and criteria were used to identify items and factors for inclusion in the final factor solution which had been discussed elsewhere. The factor pattern matrix resulting from the exploratory factor analysis consists of factor loadings that are analogous to partial standardized regression coefficients (betas) in a multiple regression analysis, whereas the factor structure matrix consists of zero-order correlations between each indicator and the factors then behave as in an orthogonal rotation. Third, eigen value criterion (one or close to 1) was used to guide the initial number of factors to retain. It is furthermore always important to check the communalities after factor extraction. If the communalities are low, the extracted factors account for only a little part of the variance, and more factors might be retained in order to provide a better account of the variance.

A series of iterations of factor analysis were then conducted, each, involving the elimination of items based on the value of factor loadings and the cut-off value of 0.50 . This value was assigned such that only items with loadings of at least 0.50 were retained and items with loadings exceeding 0.50 on two or more dimensions were eliminated. Final factors were separately measured for reliability; that is to say, items in each factor were summed to create a composite measure of 0.70. The coefficient Cronbach's alpha was estimated as an indicator of inter-item reliability or consistency.

Table 1. KMO and Bartlett's Test

Kaiser-Meyer-Olkin Measure of Sampling Adequacy. Bartlett's Test of Sphericity Approx. Chi-Square

df

Sig.

.631

2196.560

435

.000

Table 2. Component Matrix ${ }^{a}$

\begin{tabular}{|c|c|c|c|c|c|}
\hline & \multicolumn{5}{|c|}{ Component } \\
\hline & 1 & 2 & 3 & 4 & 5 \\
\hline Q1: Factor 1; Commitment & .670 & & -.239 & -.168 & -.438 \\
\hline Q2 Factor 1; commitment & .685 & -.200 & -.166 & -.199 & \\
\hline Q3 Factor 1; commitment & .649 & & -.287 & -.263 & \\
\hline Q4 Factor 1; commitment & .707 & & -.371 & .166 & -.114 \\
\hline Q5 Factor 1; commitment & .740 & -.207 & -.190 & & \\
\hline Q6 Factor 4; Alignment & .586 & -.139 & -.244 & .625 & \\
\hline Q7 Factor 5; Culture & .310 & -.424 & & & .671 \\
\hline Q8 Factor 3; Trust and Respect & .469 & -.389 & .645 & -.273 & -.118 \\
\hline Q9 Factor 4; Alignment & .363 & -.193 & .203 & .663 & \\
\hline Q10 Factor 5; Culture & .321 & -.362 & .242 & -.186 & .647 \\
\hline Q11 Factor 3; Trust and Respect & .454 & & .602 & .275 & \\
\hline Q12 Factor 3; Trust and Respect & .272 & -.349 & .654 & .394 & -.389 \\
\hline Q13 Factor 5; Culture & .587 & -.341 & .354 & & .647 \\
\hline Q14. Factor 2; Value and Voice & .419 & .756 & .249 & & \\
\hline Q15 Factor 2; Value and Voice & .528 & .613 & .312 & .105 & \\
\hline Q16 Factor 2; Value and Voice & .409 & .623 & -.102 & -.233 & .336 \\
\hline Q17 Factor 2; Value and Voice & .428 & .728 & .204 & & \\
\hline Q18 Factor 2; Value and Voice & .445 & .659 & & .174 & \\
\hline
\end{tabular}

Extraction Method: Principal Component Analysis.

a. 5 components extracted. 


\subsubsection{Cronbach's Reliability: Measure Reliability Check}

The data was subjected to Cronbach's reliability analysis using SPSS v.12. In general, reliability refers to the reproducibility of a measurement. In addition, internal reliability is the estimation based on the correlation among the variables comprising the set. However, in profound terms, reliability is the assurance that the items posited to measure a dimension are sufficiently related considered as a set of items to be reliable. The literature shows different methods to test reliability and this study used the alpha reliability method. Cronbach's reliability of the variable is derived by assuming that each item represents a retest of a single item however, it is not a test retest reliability.

Though widely interpreted as such, strictly speaking alpha is not a measure of uni-dimensionality either. Alpha reliability should be regarded instead as a measure of internal consistency of the mean of the items at the time of administration of the questionnaire. The analyses of reliability were performed on the pool data after performing EFA for each of the sets of items representing the dimensions of online brand equity, and their antecedents. The study followed the conventional minimum cut-off reliability level of 0.70 (or close) that is recommended for theory testing research. This value is suggested because it presumes that an item will explain at least half of the variability of the latent construct. Items were selected for each dimension until no higher reliability could be achieved. The iterative reliability of the analyses was carried out until similar items were obtained across the sample. Higher levels of Cronbach's alpha were obtained by deleting some items from the scale as they were not tapping the same construct as all of the other items.

Table 3. Case Processing Summary

\begin{tabular}{|ll|r|r|}
\hline & & $\mathrm{N}$ & \multicolumn{1}{|c|}{$\%$} \\
\hline Cases & Valid & 298 & 99.3 \\
& Excluded $^{\mathrm{a}}$ & 2 & .7 \\
& Total & 300 & 100.0 \\
\hline
\end{tabular}

a. Listwise deletion based on all variables in the procedure.

Table 4. Reliability Test

Reliability Analysis

Cronbach's $\mathrm{N}$ of Items

Alpha

.818

18

The questionnaire is reliable enough to represent the research construct. We can see that Cronbach's alpha is $\mathbf{0 . 8 1 8}$ which indicates a appropriate level of internal consistency for our scale with this specific sample.

\section{ANALYSIS AND INTERPRETATION}

The purpose of the data analysis and interpretation phase is to transform the data collected into credible evidence about the development of the intervention and its performance. For interpretation data, Statistical tools are used like Pie chart for showing the percentage of respondents towards various variables which are used to assess the effect. The responses to the question were analyzed for all the respondents data.

\subsection{Multiple Regression Analysis}

Multiple regression analysis is a powerful technique used for predicting the unknown value of a variable from the known value of two or more variables- also called the predictors. By multiple regression, we mean models with just one dependent and two or more independent (exploratory) variables. The variable whose value is to be predicted is known as the dependent variable and the ones whose known values are used for prediction are known independent (exploratory) variables. Multiple regression is a linear transformation of the $X$ variables such that the sum of squared deviations of the observed and predicted $\mathrm{Y}$ is minimumized. The prediction of $\mathrm{Y}$ is accomplished by the following equation:

$$
Y_{i}^{\prime}=b_{0}+b_{1} X_{1 i}+b_{2} X_{2 i}+\ldots+b_{k} X_{k i}
$$

The "b" values are called regression weights and are computed in a way that minimizes the sum of squared deviations.

$$
\sum_{i=1}^{N}\left(Y_{i}-Y_{i}^{\prime}\right)^{2}
$$

The target population is 300 , (150 employees each of Banks and Teaching faculty). In our research report we target employees of banking and teaching faculty of different colleges. 


\subsubsection{Banking Sector:}

Table 5. Model Summary ${ }^{\mathrm{b}}$

\begin{tabular}{|l|r|r|r|r|r|}
\hline Model & $\mathrm{R}$ & R Square & $\begin{array}{c}\text { Adjusted R } \\
\text { Square }\end{array}$ & $\begin{array}{c}\text { Std. Error of the } \\
\text { Estimate }\end{array}$ & Durbin-Watson \\
\hline 1 & $.639^{2}$ & .345 & 1.090 & 2.27791 & 1.906 \\
\hline
\end{tabular}

a. Predictors: (Constant), CULTURE, COMMITMENT, ALIGENMENT, VALUE_VOICE

b. Dependent Variable: TRUST_RESPECT

Analysis of the regression coefficients and seeing the value of R square we find that nearly 34 of the contribution by the independent on dependent.

Table 6. ANOVA

\begin{tabular}{|ll|r|r|r|r|r|}
\hline Model & & Sum of Squares & Df & Mean Square & F & Sig. \\
\hline 1 & Regression & 95.355 & 4 & 23.839 & 4.594 & $.002^{a}$ \\
& Residual & 736.822 & 142 & 5.189 & & \\
& Total & 832.177 & 146 & & & \\
\hline
\end{tabular}

a. Predictors: (Constant), CULTURE, COMMITMENT, ALIGENMENT, VALUE_VOICE

b. Dependent Variable: TRUST_RESPECT

$\mathrm{H}_{0}$ : There is no significant relationship between the independent and dependent variables

$\mathrm{H}_{\mathrm{A}}$ : There is significant relationship between the independent and dependent variables

\section{The Null Hypothesis is rejected because the tabulated value 2.37 of $F$ is less than calculated 4.6}

\subsubsection{Teaching Institutions:}

Table 7. Model Summary

\begin{tabular}{|l|r|r|r|c|}
\hline Model & $\mathrm{R}$ & R Square & $\begin{array}{c}\text { Adjusted R } \\
\text { Square }\end{array}$ & $\begin{array}{c}\text { Std. Error of the } \\
\text { Estimate }\end{array}$ \\
\hline 1 & $.557^{2}$ & .310 & .291 & 2.00194 \\
\hline
\end{tabular}

a. Predictors: (Constant), CULTURE, VALUE_VOICE, ALIGENMENT, COMMITMENT

Analysis of the regression coefficients and seeing the value of $\mathrm{R}$ square we find that nearly 31 of the contribution by the independent on dependent.

Table 8. ANOVA ${ }^{\mathrm{b}}$

\begin{tabular}{|ll|r|r|r|r|r|}
\hline Model & & Sum of Squares & Df & Mean Square & F & Sig. \\
\hline 1 & Regression & 259.566 & 4 & 64.892 & 16.191 & $.000^{\mathrm{a}}$ \\
& Residual & 577.118 & 144 & 4.008 & & \\
& Total & 836.685 & 148 & & & \\
\hline
\end{tabular}

a. Predictors: (Constant), CULTURE, VALUE_VOICE, ALIGENMENT, COMMITMENT

b. Dependent Variable: TRUST_RESPECT

$\mathrm{H}_{0}$ : There is no significant relationship between the independent and dependent variables

$\mathrm{H}_{0}$ : There is significant relationship between the independent and dependent variables

\section{The Null Hypothesis is rejected because the tabulated value 2.37 of $F$ is less than calculated}

16.1

\subsubsection{Cummulative Data:}

The modelled independent variables viz. culture, value and voice, alignment and commitment contribute towards $36 \%$ of the explained relationship when the cumulative responses were calculated. Rest all is contributed to unknown factors.

Table 9. Model Summary

\begin{tabular}{|l|r|r|r|r|}
\hline Model & $\mathrm{R}$ & \multicolumn{1}{|c|}{ R Square } & \multicolumn{1}{c|}{$\begin{array}{c}\text { Adjusted R } \\
\text { Square }\end{array}$} & $\begin{array}{c}\text { Std. Error of the } \\
\text { Estimate }\end{array}$ \\
\hline 1 & $.604^{2}$ & .365 & .316 & 2.63803 \\
\hline
\end{tabular}

a. Predictors: (Constant), CULTURE, VALUE_VOICE, ALIGENMENT, COMMITMENT 


\subsubsection{Hypothesis Testing; F Test}

In case of hypothesis the ANOVA Table indicates the following results.

$\mathrm{H}_{0}$ : There is no significant relationship between the independent and dependent variables

$\mathrm{H}_{0}$ : There is significant relationship between the independent and dependent variables

Table 10. ANOVA ${ }^{b}$

\begin{tabular}{|ll|r|r|r|r|r|}
\hline Model & & Sum of Squares & Df & Mean Square & F & Sig. \\
\hline 1 & Regression & 22.601 & 4 & 5.650 & 13.880 & $.000^{2}$ \\
& Residual & 57.399 & 141 & .407 & & \\
& Total & 80.000 & 145 & & & \\
\hline
\end{tabular}

a. Predictors: (Constant), CULTURE, VALUE_VOICE, ALIGENMENT, COMMITMENT

b. Dependent Variable: TRUST_RESPECT

The tabulated value is 3.32. Since the calculated value is more than tabulated we reject the Null Hypothesis and accept the alternate.

\section{CONCLUSION:}

Table 11. Conclusion

\begin{tabular}{|c|c|c|c|c|c|c|}
\hline \multirow[t]{2}{*}{ QUESTIONS } & \multicolumn{3}{|c|}{ BANKS } & \multicolumn{3}{|c|}{ INSTITUTION } \\
\hline & MEAN & $\begin{array}{l}\text { STD. } \\
\text { DEVIATIO } \\
\mathrm{N}\end{array}$ & $\begin{array}{l}\text { VARIANCE } \\
\text { S }\end{array}$ & MEAN & $\begin{array}{l}\text { STD. } \\
\text { DEVIATIO } \\
\mathrm{N}\end{array}$ & $\begin{array}{l}\text { VARIANC } \\
\text { ES }\end{array}$ \\
\hline $\begin{array}{l}\text { Employee engagement is a part of employee } \\
\text { retention strategy }\end{array}$ & 1.53 & .673 & 4.53 & 2.16 & 1.237 & 1.531 \\
\hline $\begin{array}{l}\text { Engaged employees want to stay with the company } \\
\text { and develop their career }\end{array}$ & 1.72 & .687 & .471 & 2.46 & 1.156 & 1.337 \\
\hline $\begin{array}{l}\text { Employee engagement is a measurable degree of } \\
\text { an employee's positive or negative emotional } \\
\text { attachment to their job. }\end{array}$ & 1.93 & .769 & .592 & 2.42 & .892 & .796 \\
\hline $\begin{array}{l}\text { Employee engagement adds to the nature of the } \\
\text { work which is mentally stimulating day-to-day. }\end{array}$ & 2.33 & .932 & .868 & 2.55 & 1.121 & 1.256 \\
\hline $\begin{array}{l}\text { Supported by line manager and colleagues is must } \\
\text { for employee engagement. }\end{array}$ & 1.91 & .846 & .716 & 2.20 & .920 & .846 \\
\hline $\begin{array}{l}\text { My organisation focus on employee voice which } \\
\text { listens to employees and involves and consults them } \\
\text { in decision-making. }\end{array}$ & 2.16 & .868 & .753 & 2.33 & 1.184 & 1.403 \\
\hline $\begin{array}{l}\text { My organisation Involves employees in creating } \\
\text { value }\end{array}$ & 1.81 & .814 & .663 & 2.25 & 1.187 & 1.409 \\
\hline $\begin{array}{l}\text { In my organisation autonomy and support are } \\
\text { valued }\end{array}$ & 2.17 & .975 & .951 & 2.61 & 1.257 & 1.581 \\
\hline $\begin{array}{l}\text { My organisation focuses on cultivating strong two- } \\
\text { way conversations between management and staff }\end{array}$ & 1.9933 & .81510 & .664 & 2.6200 & 1.21881 & 1.486 \\
\hline In my organisation employee opinion matters & 2.01 & .912 & .832 & 2.64 & 1.211 & 1.467 \\
\hline $\begin{array}{l}\text { Engaged employees perceive the ethos and values } \\
\text { of the organization positively }\end{array}$ & 2.05 & .784 & .615 & 2.40 & 1.141 & 1.302 \\
\hline
\end{tabular}




\begin{tabular}{|l|l|l|l|l|l|l|}
\hline $\begin{array}{l}\text { My Company focusing on engagementprovide } \\
\text { respectful treatment of employees }\end{array}$ & 2.06 & .821 & .674 & 2.49 & 1.134 & 1.285 \\
\hline $\begin{array}{l}\text { Engagement cancreate a good image infront of the } \\
\text { customers }\end{array}$ & 2.09 & .915 & .837 & 2.27 & 1.053 & 1.110 \\
\hline $\begin{array}{l}\text { Theemployee feels that managers and colleagues } \\
\text { "walk the talk' in tems of the company's values }\end{array}$ & 2.31 & 1.050 & 1.103 & 2.59 & 1.136 & 1.291 \\
\hline $\begin{array}{l}\text { Employee engagement strengthens the bond } \\
\text { between employees of the organization }\end{array}$ & 2.01 & .879 & .772 & 2.17 & 1.041 & 1.084 \\
\hline Engagement leads to clanity of job expectations & 1.83 & .847 & .717 & 2.35 & .958 & .918 \\
\hline $\begin{array}{l}\text { Engagement is achieved through effective Intemal } \\
\text { Employee Communications }\end{array}$ & 2.15 & .849 & .721 & 2.07 & .816 & .667 \\
\hline $\begin{array}{l}\text { Employee engagementleads to career } \\
\text { advancementimprovement opportunities }\end{array}$ & 1.58 & .813 & .661 & 2.21 & 1.145 & 1.310 \\
\hline
\end{tabular}

It can be inferred from the comparative analysis as mentioned above that the Standard deviation values are small in case of banks and it is more in case of educational institutions. One can explain the deference due to higher order understanding among the teaching fraternity about the concept of employee engagement.

Results from this study contributed to the limited empirical research on the topic of employee engagement. Specifically, it contributed the first statistical information about rates of engagement among staff in a banks and higher educational institutes. Because employee engagement is now understood to be a critical component of successful organizational outcomes, it needs to be closely examined in the social work field, if for no other reason that agencies are held increasingly more accountable for outcomes, and funding is often tied to success rates. An engaged staff can contribute significantly to reaching positive outcomes. Therefore, the engagement concept should be at the forefront of social work research and policy implementation.

The multivariate analysis and model also to a bigger extent explain the similarity in the interpretation of the concept of employee engagement. In fact the value of R2 for both ha a marginal difference of around 0.3. When the complete data was analyzed it also did not show any remarkable difference between the hypothesized models.

The F statistics point toward rejection of the null hypothesis of no difference and thus a positive relationship is established. Thus the surrogate proxy that trust and respect are indicators of organisational initiatives towards employee engagement hold ground.

Table 12. Results

\begin{tabular}{|c|c|c|}
\hline QUESTIONS & $\begin{array}{l}\text { MAJORITYOF RESPONDENT IN } \\
\text { BANKS }\end{array}$ & MAJORITY OF RESPONDENT IN \\
\hline Employee engagement is a part of employee retention strategy & $58 \%$ Strongly agree & $38 \%$ Agree \\
\hline $\begin{array}{l}\text { Engaged employees want to stay with the company and develop } \\
\text { their career }\end{array}$ & $52 \%$ approx Agree & $55 \%$ Agree \\
\hline $\begin{array}{l}\text { Employee engagement is a measurable degree of an employee's } \\
\text { positive or negative emotional attachment to their job. }\end{array}$ & $45 \%$ approx Agree & $54 \%$ approx Agree \\
\hline $\begin{array}{l}\text { Employee engagement adds to the nature of the work which is } \\
\text { mentally stimulating day-to-day. }\end{array}$ & $35 \%$ approx Agree & $46 \%$ approx Agree \\
\hline $\begin{array}{l}\text { Supported by line manager and colleagues is must for employee } \\
\text { engagement. }\end{array}$ & $40 \%$ Agree & $51 \%$ approx Agree \\
\hline $\begin{array}{l}\text { My organisation focus on employee voice which listens to } \\
\text { employees and involves and consults them in decision-making. }\end{array}$ & 43\% approx Agree & $32 \%$ Agree \\
\hline
\end{tabular}




\begin{tabular}{|l|l|l|}
\hline My organisation Involves employees in creating value & $43 \%$ approx Agree & $42 \%$ approx Agree \\
\hline In my organisation autonomy and support are valued & $42 \%$ Agree & $29 \%$ approx Agree \\
\hline $\begin{array}{l}\text { My organisation focuses on cultivating strong two-way } \\
\text { conversations between management and staff }\end{array}$ & $50 \%$ Agree & $35 \%$ Somewhat agree \\
\hline In my organisation employee opinion matters & $40 \%$ approx Agree & $40 \%$ Agree \\
\hline $\begin{array}{l}\text { Engagedemployees perceive the ethos and values of the } \\
\text { organization positively }\end{array}$ & $49 \%$ approx Agree & $34 \%$ approx Agree \\
\hline $\begin{array}{l}\text { My Company focusing on engagementprovide respectul } \\
\text { treatment of employees }\end{array}$ & $45 \%$ approx Agree & $42 \%$ approx Agree \\
\hline Engagement can createa good image infront of the customers & $42 \%$ Agree & $46 \%$ Agree \\
\hline $\begin{array}{l}\text { The employee feels thatmanagers and colleagues "walk the talk" } \\
\text { in tems offthe company's values }\end{array}$ & $29 \%$ approx Agree & $38 \%$ Agree \\
\hline $\begin{array}{l}\text { Employee engagementstrengthens the bond between } \\
\text { employees of the organization }\end{array}$ & $46 \%$ approx Agree & $44 \%$ approx Agree \\
\hline Engagement leads to clanity of job expectations & $41 \%$ approx Strongly agree & $52 \%$ approx Agree \\
\hline $\begin{array}{l}\text { Engagementis achieved through effective Intemal Employee } \\
\text { Communications }\end{array}$ & $40 \%$ Agree & $48 \%$ approx Agree \\
\hline $\begin{array}{l}\text { Employee engagementleads to career } \\
\text { advancementimprovement opportunities }\end{array}$ & $58 \%$ approx Strongly agree & $36 \%$ approx Agree \\
\hline
\end{tabular}

\section{RECOMMENDATION}

Work Trends Report (2010) by the Kenexa Research Institute, on the basis of an international survey has demonstrated that, Employees are engaged by:

- Leaders who inspire confidence in the future.

- Managers who respect and appreciate their employees.

- Exciting work that employees know how to do.

- Employers who display a genuine responsibility to employees and communities.

Paul Marciano, author of "Carrots and Sticks Don't Work: Build a Culture of Employee Engagement with the Principles of RESPECT." Employee engagement depends upon the extent to which individuals respect their organization and its leadership, and feel respected. There are seven critical ways in which managers can show respect to their employees.

- Recognition: Thanking employees and acknowledging their contributions on a daily basis.

- Empowerment: Providing employees with the tools, resources, training, and information they need to be successful.

- Supportive feedback: Giving ongoing performance feedback - both positive and corrective.

- Partnering: Fostering a collaborative working environment.

- Expectation setting: Establishing clear performance goals and holding employees accountable.

- Consideration: Demonstrating thoughtfulness, empathy, and kindness.

The Center for Effective Organizations at University of Southern California and Research Data Technology, Inc. When observations in relation to employee engagement were subjected to multivariate analyses - basically, the simultaneous observation and analysis of many, many outcome variables - the same result appeared every time. When trust, values and a purpose-driven mission exist to a statistically significant degree and guide leadership, decision-making and behavior, these "enablers" give rise to a highly inspired group of super-engaged employees.

The analysis also tells us that when trust, values and a purpose-inspired mission do not drive behavior in a company, far fewer of these engagement traits exist. Even worse, extremely low levels of these engagement sources produce a "disconnected" group of employees who work against or even sabotage company objectives. Every organization has some supply of trust, values and mission; however, the research shows that the companies with super-engaged employees treat 
these core enablers as a reactor. When this reactor "heats up," it produces truly inspired employees who want to build cathedrals rather than merely lay bricks.

1. Commitment: Employees who are engaged in their work and committed to their organizations give organizations crucial competitive advantages-including higher productivity and lower employee turnover. Loyalty and intent to stay with the organization.

2. Value and voice: It sounds relatively straight forward but actually generating the conditions to allow it to flourish are quite challenging - a key one is to give your employees a value and voice in the company so that they feel able to contribute in its running and hence feel engaged in its success.

3. Alignment: fit between individual and organizational values.

4. Culture: The best way to increase employee engagement is to focus on creating a culture of engagement. We define culture as including the practices, shared mindset and ethos of an organization.

5. This research documents that it is the combination of creating a high performance organization and building an engaged workforce that positions an organization for its greatest success. The constructs under consideration are performance excellence variables viz. commitment, value and voice, alignment and culture and trust and respect as a proxy for employee engagement. The indices that measure these constructs shine as potent employee-based leading indicators of business success. The higher the scores on these indices, the betterpositioned employees are to deliver the organization's value proposition to the marketplace.

Focusing on these factors provides a clear path forward. Continuous improvement on these constructs and measures will impact critical fiscal performance metrics - a prize coveted — for which leaders are running their race.

\section{LIMITATION OF THE STUDY}

Although this research was carefully prepared, we are still aware of its limitations and shortcomings. There are two noteworthy limitations of this study: generalizability and longitudinal effects. The generalizabilty of these research findings are limited because they were generated in an exploratory quantative inquiry. The research design was not intended to produce results that account for or predict the behavior of a wide classification of people as most experimental, hypothesis-testing studies are. This liability was clear at the outset. However, because the inquiry generated a relatively clear and specific Grounded Theory that can be applied to practical experiences, it should be relatively easy to design a series of focused hypothesis-testing studies to experimentally verify and expand the theory generated here. These studies would be much more likely to produce findings which can be generalized to larger classifications of people.

Second, time and budget limitations made it impractical to assess how narrative-based processing might have influenced participants' long-term thinking over multiple months or years. Future studies might consider narrative-based experiential learning interventions which are followed up with longitudinal check-ups for months or longer to explore if and how longterm after-effects actually occur. To sum up the limitations were;

- $\quad$ Time limit

- Respondent's refusal to co-operate.

- Some respondents replied half heartedly.

- Some respondents gave incomplete information.

- The first limitation concerns the cross-disciplinary nature of this research project.

- Future research would have been more convincing if the researchers have related more factors to competitiveness of banks and higher education.

\section{REFERENCES}

[1] Alderfer, C.P. 1972. Human needs in organisational settings. New York, Free Press of Glencoe.

[2] Balain S, Sparrow P. 2009. Engaged to Perform: A new perspective on employee engagement: Executive Summary, Lancaster University Management School

[3] Baumruk, R. 2004. The missing link: the role of employee engagement in business success, workspan, vol 47, pp48-52.

[4] Brown, S. P. 1996. A meta-analysis and review of organizational research on job involvement. Psychological Bulletin, 120, 235-255.

[5] Buhler, P. 2006.Engaging the workforce: a critical initiative for all organizations SuperVision, 67(9), 18-20.

[6] Chartered institute of personnel and development (cipd) 2006c working life: employee attitudes and engagement 2006 research report.

[7] Charles woodruffe 2006. Employee Engagement - the real secret of winning a crucial edge over your rivals manager motivation

[8] Coffman, C., \& Gonzalez-Molina, G. 2002. Follow this path. How the world's greatest organizations drive growth by unleashing human potential. Warner Books.

[9] Cohen, L. and Manion, L., Research Methods in Education, London: Groom Helm Ltd., 1980.

[10] Costello \& Osborne, Exploratory Factor Analysis Practical Assessment Research \& Evaluation, Vol 10, No 79

[11] Cropanzano, R. and Mitchell, M.S. 2005. Social exchange theory: an interdisciplinary review, Journal of Management, Vol 31, pp874-900.

[12] Department of health 2009. the nhs constitution for england. available at: www.dh.gov.uk/en/publicationsandstatistics/publications/Publications policy andguidance/dh_093419 
[13] Kahn, W.A. 1990. Psychological conditions of personal engagement and disengagement at work, Academy of Management Journal, Vol 33, pp692-724.

[14] Frank, f.d., finnegan, r.p. and taylor, c.r. 2004. 'the race for talent: retaining and engaging workers in the 21st century', human resource planning, vol 27, no 3, pp12-25.

[15] Frauenheim, E. 2006. Study: Workers are disengaged but staying put. Workforce Management, 85(22).

[16] Freud, S. 1922. in Ferguson, A. (2007) 'Employee engagement: Does it exist, and if so, how does it relate to performance, other constructs and individual differences?' [online] Available at: http://www.lifethatworks.com/Employee-Engagement.prn.pdf [Accessed 20th June 2007]

[17] Garner, B. R., Knight, K., \& Simpson, D. D. (2007). Burnout among corrections based drug treatment staff. International Journal of Offender Therapy and Comparative Criminology, 51(5), 510-522.

[18] Goffman, E. (1961) Encounters: Two Studies in the Sociology of Interaction. Indianapolis, Bobbs-Merrill Co.

[19] Ferguson, A. (2007) 'Employee engagement: Does it exist, and if so, how does it relate to performance, other constructs and individual differences?' [online] Available at: http://www.lifethatworks.com/EmployeeEngagement.prn.pdf [Accessed 20th June 2007]

[20] Harter, J. K., Schmidt, F. L., Killham, E. A. \& Agrawal, S., T. L. (2009). Q12® Meta-Analysis: The Relationship Between Engagement at Work and Organisational Outcomes. Retrieved 5 June 2011, from www.gallup.com/consulting/ File/126806/MetaAnalysis_Q12_White Paper_2009.pdf

[21] Harter, J. K., Schmidt, F. L., \& Hayes, T. L. (2002). Business-unit-level relationship between employee satisfaction, employee engagement, and business outcomes: A meta-analysis. Journal of Applied Psychology, 87, 268-279

[22] Heskett, J., Jones, T., Loveman, G., Sasser, W. E., and Schlesinger, L. (1994). Putting the Service-Profit Chain to Work. Harvard Business Review, March-April,164-174.

[23] Hobel, J. (2006). Loyal staff worth the effort. Canadian HR Reporter, 19(19), 26-26.

[24] Holbeche, L. and Springett, N. (2003) In Search of Meaning in the Workplace. Horsham,Roffey Park.

[25] Importance of Employee Engagement http://blog.allegiance.com/2010/08/the-importance-of-employeeengagement/

[26] ISR (2004) International Survey Research. [Online] Available at: www.isrsurveys.com [Accessed 6th July]

[27] Kahn, w.d. (1990). psychological conditions of personal engagement and disengagement at work. academy of management journal, 33(4): 692-724.

[28] Lockwood, N. R. (2007). Leveraging Employee Engagement for Competitive Advantage.SHRM Research Quarterly, 2-11.

[29] Loehr, J., \& Schwartz, T. (2003). The power of full engagement. The Free Press.

[30] Lovett, S., Zeiss, A. M., \& Heinemann, G. D. (2002). Assessment and development: Now and in the future, Heinemann, Gloria D. (Ed); Zeiss, Antonette M. (Ed). (2002). Team performance in health care: Assessment and development. Issues in the practice of psychology. (pp. 385 400)

[31] Luthans F, Peterson SJ (2002), 'Employee engagement and manager self- efficacy: implications for managerial effectiveness and development', Journal of Management Development, 21(5), 376-387

[32] Majors, M. S., \& Sedlacek, W. E. (2001). Using factor analysis to organize student services. Journal of College Student Development, 42(3), 2272-2278.

[33] Maslow, A. (1954) Motivation and Personality. New York, Harper and Row.

[34] Maslach, C., Schaufelli, W. B., \& Leiter, M. P. (2001). Job burnout. Annual Review of Psychology, 52, $397-422$.

[35] May, D.R. Gilson, R.L. and Harter, L.M. (2004) 'The psychological conditions of meaningfulness, safety and availability and the engagement of the human spirit at work',

[36] Morris, S. B. (2001). Sample size required for adverse impact analysis. Applied HRM Research, 6(1-2), 13-32

[37] Rampersad, H. (2006). Self-examination as the road to sustaining employee engagement and personal happiness. Performance Improvement, 45(8), 18-25.

[38] Richman, a. (2006) 'everyone wants an engaged workforce how can you create it?' workspan, vol 49, pp36-39.

[39] Robinson, d., perryman, s. and hayday, s. (2004) the drivers of employee engagement. brighton: institute for employment studies.

[40] Rotter JB (1990), 'Internal vs. external control of reinforcement: a case history of a variable, American Psychologist, 45(4), 489-493, www.managementstudyguide. com

[41] Saks, A.M. (2006) 'Antecedents and consequences of employee engagement', Journal of Managerial Psychology, Vol 21, No 6, pp600-619

[42] Schaufeli wb, salanova m, gonzalez-roma v, bakker ab (2002). 'the measurement of engagement and burnout: a two sample confirmatory factor analytic approach'. journal of happiness studies, vol 3, pp 71-92.

[43] Schaufeli, W. B., Bakker, A. B. (2004). Job demands, job resources, and their relationship with burnout and engagement: a multi-sample study. Journal of Organizational Behavior, 25, 293-315.

[44] Scottish Executive SocialResearch (2007), Employeeengagementin the Public Sector: a review of literature, www.scotland.gov.uk/ Publications/2007/05/09111348/3

[45] Seligman, M. P., \& Csikszentmihalyi, M. (2000). Positive psychology: An introduction. American Psychologist, 55, 5-14.

[46] Shaw, k. (2005) 'an engagement strategy process for communicators', strategic communication management, vol 9, no 3, pp26-29.

[47] Silverman (2004) Approaches for Diverse Populations. New York and London: Routledge, pp. $223-243$.

[48] Slater, P.E. (1966) Microcosms. New York, Wiley in Ferguson, A. (2007) 'Employee 
[49] engagement: Does it exist, and if so, how does it relate to performance, other constructs and individual differences?' [online] Available at: http://www.lifethatworks.com/ Employee- Engagement.prn.pdf [Accessed 20th June 2007]

[50] Smith, K.K. and Berg, D.N. (1987) Paradoxes of Group Life. San Francisco, Jossey-Bass. Journal of Occupational and Organisational Psychology, Vol 77, pp11-37.

[51] Soderfeldt, M., Soderfeldt, B., \& Warg L.E.. (1995). Burnout in Social Work. Social Work, 40(5), 638-646.

[52] Taleo Research (2009). Alignment Drives Employee Engagement and Productivity. Retrieved 29 May 2011 from http://www.taleo.com

[53] Towers Perrin (2003). Working Today: Understanding What Drives Employee Engagement. The 2003 Towers Perrin Talent Report.Retrieved 15 June 2011, from http://www.towersperrin.com/tp/getwebcachedoc?webc=hrs/usa/2003/200309/talent 2003.pdf

[54] Truss, c., soane, e., edwards, c., wisdom, k., croll, a. and burnett, j. (2006) working life: employee attitudes and engagement 2006. london, cipd.

[55] Twnsend, p. I., \& gebhardt, j. e. (2007). the executive guide to understanding and implementing employee engagement programs. milwaukee, wi: asq quality press.

[56] Ayers, K.E. (2006). Engagement is not enough. Integro Leadership Institute LLC.

\section{Author' biography with Photo}

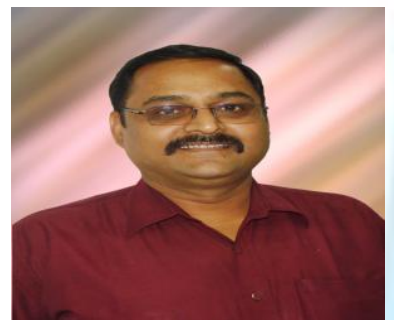

Dr. Anil Kumar Singh is working as a Proffessor in the Institute of Business Management at GLA University. He has industrial exposure of about 8 years in flexible packaging, Pharma and Consultancy. He holds twin MBA with specialization in Finance and Marketing, and has been awarded Ph.D in the area of Strategic Management. Having spent nearly 21 years in industry and academia, he has to his credit more than 15 publications in Journals of Repute. He can be reached at anil.singh.kr@gmail.com

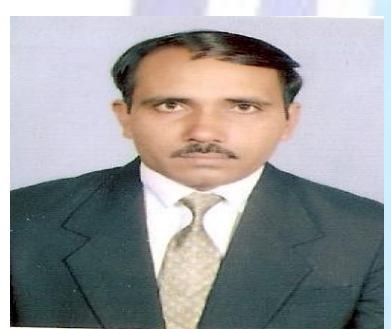

Dr. Priyender Yadav is working as an Assistant Professor in the Institute of Business Management at GLA University. He holds masters in statistics, MBA in Marketing and is UGC-NET qualified. His Ph.D is in the area of complex modeling of Buyer behavior. He has more than 10 Years of Teaching and research experience. He holds to his credit more than 14 Publications in Journals of Repute. He can be reached at priyender@gmail.com 